UDC 930.1

LBC 66.287.60

\title{
TRANSFORMATION OF STATES IN THE ERA OF GLOBALIZATION: SYNERGISTIC ASPECT
}

\author{
Alexey F. Rodukov \\ The Bonch-Bruevich Saint-Petersburg State University of Telecommunications, \\ Saint Petersburg, Russian Federation
}

\begin{abstract}
Social synergy considers the historical process as a movement along a logarithmic (narrowing and going to infinity) spiral that is a "golden spiral", obeying the law of differentiating and integrating of social ideals (V.P. Branskiy). The totalitarian ideal expresses the cult of responsibility (order) and the anarchist ideal expresses the cult of freedom (chaos). The society is committed to an optimal balance of chaos and order, freedom and responsibility. Thus, in the concept of "regimes with exacerbation" by S.P. Kurdyumov the phase transition (from one state to another) is associated with an increasing tendency to speeding up the process. The history shows rather "oscillation" tendencies of strengthening or weakening of the state. Extremes are deconstructive. Thus the processes of establishing the optimal ratio between chaos and order in society are reflected in the law of hierarchical compensation by E.A. Sedov. However, the self-organization of the state as such is carried out as an endless tendency towards the common to all mankind ideal and it is non-linear, contrary to the classics of Marxism. Nowadays, the fateful for the state contradiction between the democratic process of "degovernmentalization", on the one hand, and the "capture" of supranational institutions and functions first by the national and then transnational corporations, on the other, is being actualized. The privatization of property and the non-admission of the "rest" of population to this process leads to the de-socialization of the state. The goal of a corporation-state is to weaken or even eliminate the national identity and sovereignty of a nation-state. The state rejection of social functions and guarantees means its strengthening. On the contrary, the development and functioning of the institutions of the societal state and civil society goes under state patronage and leads to the removal of the state monopoly from the several sides of the life of society.
\end{abstract}

Key words: order, chaos, differentiation and integration of ideals, nation-state, corporation-state, globalization, deglobalization.

УДК 930.1

ББК 66.287 .60

\section{ТРАНСФОРМАЦИИ ГОСУДАРСТВ В ЭПОХУ ГЛОБАЛИЗАЦИИ: СИНЕРГЕТИЧЕСКИЙ АСПЕКТ}

\author{
Алексей Федорович Родюков \\ Санкт-Петербургский государственный университет телекоммуникаций им. проф. М.А. Бонч-Бруевича, \\ г. Санкт-Петербург, Российская Федерация
}

\footnotetext{
Аннотация. Социальная синергетика рассматривает исторический процесс как движение по логарифмической (сужающейся и уходящей в бесконечность) спирали - «золотой спирали», подчиняющееся закону ণे дифференциации и интеграции социальных идеалов (В.П. Бранский). Тоталитарный идеал выражает культ $\hat{\theta}$ ответственности (порядка), а анархистский - культ свободы (хаоса). Общество стремится к оптимальному соотношению хаоса и порядка, свободы и ответственности. Процессы установления оптимального соотношения хаоса и порядка в обществе находят выражение в законе иерархических компенсаций Е.А. Седого. В Вонцепции «режимов с обострением» С.П. Курдюмова фазовый переход (одного состояния в другое) сопряжен с нарастающей тенденцией к убыстрению процесса. В истории видны, скорее, «колебательные» тенденции либо усиления, либо ослабления государства. При этом крайности деконструктивны. Самоорга-
} 
низация государства как такового осуществляется в бесконечном движении к общечеловеческому идеалу и является, вопреки классикам марксизма, нелинейной. В настоящее время актуализируется судьбоносное для государства противоречие между демократическим процессом «разгосударствления», с одной стороны, и «захватом» надгосударственных институтов и функций сначала национальными, а затем и транснациональными корпорациями, с другой стороны. Приватизация имущества и недопущение к этому процессу «остального» населения ведет к десоциализации государства. Цель корпорации-государства - ослабление или даже устранение национальной идентичности и суверенитета государства-нации. Отказ государства от социальных функций и гарантий означает его усиление. Напротив, развитие и функционирование институтов социального государства и гражданского общества идет под государственным патронажем и приводит к снятию государственной монополии с ряда сторон жизни общества.

Ключевые слова: порядок, хаос, дифференциация и интеграция идеалов, государство-нация, государство-корпорация, глобализация, деглобализация.

Проблема трансформации государства задается двумя крайними позициями: теориями «отмирания», или, точнее, «засыпания государства» [Энгельс 1961, 291-292] и его «усиления», однако не сводится к ним. По сути, это вопрос о том, сможет ли общество когда-нибудь освободиться от государства в целом или от ряда отживших его функций в частности, заменить его другой организацией, что ждет государство в недалеком и отдаленном будущем? Однако возможен иной (третий) подход к решению данной проблемы, опирающийся на методологию социальной синергетики. По нашему мнению, именно он обладает эвристической продуктивностью для решения сформулированной проблемы.

Претензии синергетической философии выступать в качестве методологии познания общества не раз подвергались сомнению на том основании, что она, по своему генезису, является естественнонаучной дисциплиной. При этом была намечена возможность ее дальнейшего развития в качестве теории самоорганизации общества как сложной диссипативной структуры [Розин 2004, 85-102]. На этом пути социальная синергетика развила свой категориальный аппарат, сопоставимый с системой философских категорий, и сформулировала ряд фундаментальных законов: закон иерархизации и деиерархизации социальных структур, закон дифференциации и интеграции идеалов, закон релевантности. Ее концептуальная основа отражает такие уровни самоорганизации социума, как феноменологический, эссенциальный и эсхатологический (связанный с проблемой глобального будущего человечества) [Бранский, Пожарский (ред.) 2009].

Сформулированная проблема существенно усложняется под влиянием фундаменталь- ных процессов глобализации. Глобализация в качестве нового явления социальной жизни осмысливается как путь к глобальному единству через потенциально бесконечное локальное разнообразие, что противоречит и ставит под сомнение линеарную перспективу развития [Бранский и др. 2017, 56].

На феноменальном уровне история показывает, что в жизни общества происходят процессы как усиления, так и ослабления государства даже в рамках одной и той же формации. Подобные процессы могут базироваться на разных приоритетах, целях и формах государств. Существуют периоды «закрытого» и «открытого» общества, господство государственной экономики сменяется господством экономики либеральной, либерализм тоталитаризмом, порядок - хаосом, а коллективизм - индивидуализмом. К тому же на первый план могут выходить то преимущественно внутренние детерминации, то внешние. Так проявляется закон дифференциации и интеграции идеалов, объясняющий, «почему периодическая смена идеалов и обусловливаемая ею переоценка ценностей является исторически необходимым процессом» [Бранский, Пожарский (ред.) 2009, 96-97]. При этом концепции идеологического тоталитаризма и открытого общества составляют оппозицию, в рамках которой исход борьбы является совершенно непредсказуемым [Бранский и др. 2017, 56].

На эссенциальном уровне теория постепенного отмирания («засыпания») государства является утопичной - по крайней мере, пока не вызрели полностью все материальные условия для этого - и слабо отвечает синергетическим принципам. Так, в концепции «режимов с обострением» Е.Н. Князевой и С.П. Кур- 
дюмова фазовый переход (одного состояния в другое) сопряжен с нарастающей тенденцией - убыстрением процесса [Князева, Курдюмов 2002]. Однако история показывает, скорее, «колебательные» тенденции усиления либо ослабления государства, а в глобальных геополитических процессах - «убыстрение локального хаоса», связанного с разрушением целого ряда государств.

С позиций социальной синергетики исторический процесс предстает как движение по логарифмической (сужающейся и уходящей в бесконечность) спирали - «золотой спирали». В этом движении происходит дифференциация и интеграция социальных идеалов. Например, смысл существования экстремистских (крайних) идеалов - тоталитарных и анархистских - состоит в том, что они определяют направление либерального вектора развития общества. Крайние формы тоталитарных и анархистских идеалов определяют направление либерального вектора именно потому, что либеральный идеал обычно стремится в равной степени дистанцироваться от этих крайностей [Бранский, Пожарский (ред.) 2009, 76]. В данном контексте идеал сохранения и упрочнения государства выражает тенденцию тоталитаризма (культ порядка), а идеал отмирания государства тенденцию анархизма (культ свободы). И та и другая крайность недопустимы, а речь должна идти об общей тенденции установления оптимального соотношения хаоса и порядка в жизни общества. Такая тенденция находит свое выражение в законе иерархических компенсаций Е.А. Седого. Для общества оптимальное соотношение разобщенности (максимум разнообразия на нижнем уровне) и детерминированности (максимум разнообразия на верхнем уровне) должно составлять $20 \%$ / $80 \%$. Это означает, что для оптимального функционирования общества как социальной самоорганизации индивидов необходимо 80 \% упорядочивающих структур (государственно-надзорных и юридических структур и силовых ведомств) и 20 \% либерально-демократических [Седов 1995, 92-100].

С другой стороны, в социальных теориях от Платона до С. Московичи и А. Панарина проект государства приобретает все более глобальный характер и утверждается в каче- стве главного инструмента переделки мира и человека. Как бы ни пытались конкурировать с государством такие институты, как семья, церковь, наука, техника или международные организации, все равно государство берет верх в конкуренции названных «орудий преобразования».

В начале XXI в. было общепризнано, что глобализация является самым важным процессом современности, связанным преимущественно с экономической интеграцией [Sheeld (ed.) 2013]. При этом некоторые исследователи, например, Р. Робертсон, универсализируют представление о глобализации, рассматривают ее как социальную теорию и глобальную культуру [Robertson 2000]. Не отрицая экономического базиса глобализации, социальная синергетика понимает ее как интеграцию особого рода, для которой, в отличие от интеграционных процессов прошлого, характерен ряд новых признаков: всесторонность, массовость, планетарность («глобальность» в собственном смысле), спонтанность и хаотичность (неупорядоченность интеграционных процессов, наличие в интеграционном процессе случайных флуктуаций) [Бранский, Пожарский 2004, 5-7].

Государство имеет свои атрибуты в виде таких институтов, как собственность, право, власть, идеология, бюрократический аппарат. При «переходе» к негосударственному общежитию все они должны деконструироваться с ускорением. Однако процесс либерализации, наблюдаемый нами в ряде стран, к этому не ведет. Собственность сохраняется, власть маскируется под разные формы права, идеология помогает адаптироваться и сопротивляться кризисам, бюрократический аппарат далеко еще не исчерпал свой ресурс и демонстрирует постоянное обновление и рост.

Вместе с тем здесь обнаруживается некоторое противоречие: на фоне освобождения государства от тех или иных функций (например, связанных с утверждением демократии или разгосударствлением собственности) возрастает значимость негосударственных ресурсов, которые могут играть в обществе негативную, разрушительную по отношению к государству роль. Демократический процесс «разгосударствления» приводит к «захвату» надгосударственных институтов и функций 
сначала национальными, а затем и транснациональными корпорациями. Таким образом, разгосударствление как «отмирание» государства осуществляется двояким образом: как передача части государственных функций нации по горизонтали и как передача части государственных функций корпорациям по вертикали. В первом случае мы имеем дело с нацией-государством, а во втором - с корпорацией-государством [Фурцев web].

Корпорация-государство подменяет национальные политико-экономические интересы интересами различных экономических групп, выступающих в качестве представителей государства. Они приватизируют в своих (развернутых в сторону глобальной экономики) интересах характерные для нации-государства властные функции, что приводит к денационализации государства. Следующим шагом является приватизация имущества и недопущение к этому процессу «остального» населения - десоциализация государства. Цель корпорации-государства - ослабление или даже устранение национальной идентичности и суверенитета государства-нации.

Идея мировой революции теперь в руках глобалистов. Авангард глобалистов - транснациональные компании и мировая финансовая олигархия. Мировой рынок, мировое правительство, глобальная унификация и т. д. - главные условия отмирания национальных государств в процессе глобализации. По мысли марксистов и глобалистов, все страны должны сокращенно пройти «путь развитых стран» и стать частью мирового процесса, захватывающего экономику, политику, финансы и т. д.

В основе глобализации лежит либеральная идея тотального превосходства Запада (как цивилизации гуманизма и продуктивности) над Востоком (как цивилизацией маргинальности и контрпродуктивности). Западная идеология приписывает неевропейским народам в качестве культурной нормы «дикость», «агрессивность», однако коллективный Запад не раз проявлял гораздо большую жестокость и даже геноцид по отношению к иным, менее развитым этносам и государствам. В колониальную эпоху эта идеология оправдывала любые преступления против человечности, творимые колонизаторами. В основе уверенности в победе Запада лежало убеждение в уни- версальности западной культуры, ее исключительных чертах, приведших к гигантскому материальному превосходству [Фокин 2015, 182-183]. Западные либералы многое делают для реализации идеалов личностной свободы граждан своих стран (и их объединений). Однако как только речь заходит о вмешательстве в дела других, «отсталых», «недемократических», «тоталитарных» стран, либералы превращаются в жестких государственников, беря на себя политическую и идеологическую роль «мировых жандармов».

Первоначально такого рода вмешательства оценивались как процессы вестернизации «отсталых народов». Однако впоследствии процессы глобализации расширились за счет подключения таких новых «игроков»-Китая, Индии, России, для которых важен возврат к таким изначальным ценностям глобальной интеграции, как свобода торговли, обмен культурными ценностями, учет интересов всех участников процесса, отсутствие принуждения на этом пути и т. п. Тем самым проявляется нелинейность процессов глобализации и провозглашается возможность выбора ее модели - американской, европейской, азиатской, российской. Выбор модели осуществляет так называемый детектор, который состоит из сочетания процессов конкуренции и кооперации, соотношения интересов и движущих сил в обществе, господствующих идеологических и религиозных ценностей.

Прежнее западное единство приходит к концу и через новый передел мира зарождается его новая конфигурация. Одновременно ставится под сомнение не только сам уровень глобализации мира, но его смысл и пределы. Об этом свидетельствуют такие явления, как «торговые войны», рост протекционизма, выход Англии из ЕС, рост национализма и сепаратизма и многое другое.

Вместе с деглобализацией противоречия не уничтожаются, но обретают новые параметры и новые уровни конфликтности. При этом имевшие место процессы мировой интеграции замещаются новыми интеграционными и дифференциальными процессами, но уже на региональном уровне. А потому, в полном согласии с классической диалектикой и социальной синергетикой, процессы дифференциации и интеграции в реальной действительности и в сфере 
идеалов сохраняются, но их конфигурация обретает новые черты. Смысл такого сохранения в том, чтобы обеспечить на новом витке глобального аттрактора возобновление всего цикла, но при другом соотношении идеалов. При этом процессы региональной глобализации уже начинают оказывать влияние на параметры вступающих в эти новые формы взаимодействия государств. В прогностическом плане такие процессы могут привести к миропорядку, более свободному от агрессивной политики сверхдержав, какими они были в периоды борьбы за мировое господство.

Глобальное будущее общества без насилия заключается именно в формировании и реализации общечеловеческого (интерсубъективного) идеала - суператтрактора. Государственный интерес в любом случае выражен частночеловеческим идеалом. Однако нарастающая компонента общечеловеческого содержания, выраженная культурными универсалиями (добро, красота, истина, справедливость и т. д.), определяет глобальную кривую эволюции. А потому «отмирание государства» протекает в разрешении противоречий между героизмом и гуманизмом, готовностью к любым человеческим жертвам и отказом от жертв вообще, между определенностью повседневной жизни, где господствует «суета сует», и неопределенностью и запредельностью будущего, где одинаково возможны и катастрофа, и обнаружение выхода из эволюционного тупика.

В современном мире уровень физического насилия достиг беспрецедентно низких показателей; однако это обстоятельство не должно расхолаживать. Государство как аппарат сдерживания и насилия в обществе одновременно выступает фактором его воспитания и гуманизации. В общей тенденции гуманизации ответственность персонифицирована социальными институтами и государством. Ответственность - это устойчивость социума, его иерархизация. Свобода же, представленная хаотизацией, связана с расшатыванием системы и ее деиерархизацией. В таком случае отмирание государства представляется определенным этапом деиерархизации, который характеризуется снижением ответственности, дезорганизацией, дисбалансом, снижением устойчивости социума.
Таким образом, речь идет о самом содержании таких понятий, как «отмирание» и «трансформация» государств. Необходимо учитывать, в чьих интересах идут данные процессы, совершаются ли они в пользу большинства, или в пользу меньшинства, в пользу национальной самобытности и суверенитета, или обеспечивают интересы транснациональных корпораций и их диктат на международном геополитическом уровне. Необходимо также учитывать «догоняющий» или «лидирующий» тип развития государства, внешние и внутренние угрозы, ментальные особенности этноса и его национальные идеи.

С точки зрения социальной самоорганизации развитие представляет собой чередование «хаоса» и «порядка». Поэтому термин «отмирание» следует понимать скорее метафорически, поскольку отмирает только то, что входит в противоречие с социальным и экономическим прогрессом общества. Те же функции государства, которые необходимы для прогресca, наоборот, сохраняются, а при определенных конкретно-исторических условиях могут даже усиливаться. Мобилизация государственных ресурсов всегда является ответом на внутренние и внешние вызовы. Идея «атомизации» общества как проявление спонтанной свободы индивидов вовсе не означает умирания государства, но может привести к хаотизации общества, означающей утрату государством управляющей функции. Теоретическая и идеологическая поддержка этих процессов получила на Западе название «теории управляемого хаоса». Однако, как показывает исторический опыт, хаосом управлять невозможно.

В заключение следует отметить, что эмпирически фиксируемые процессы «отмирания государства», несмотря на их сложность и противоречивость, присущи различным типам государств. Наличие данного тренда в эволюции современного человечества в свете социальной синергетики может быть сопоставимо с бесконечным приближением к суператтрактору. Такое приближение требует преодоления целого ряда фундаментальных проблем, связанных с наличием материальных предпосылок отмирания государства, влиянием предрассудков массового сознания, сопротивлением элиты, достижениями научно-технического прогресса, противоречиями 
между тенденциями глобализации и отстаиванием национальных интересов. Поэтому на методологическом уровне при анализе проблем «отмирания государства» необходим переход от абстрактно-общего к конкретнообщему подходу, позволяющему исследовать конкретно-исторические формы и смыслы «отмирания» государства.

\section{СПИСОК ЛИТЕРАТУРЫ}

Бранский, Пожарский 2004 - Бранский В.П., Пожарский С.Д. Глобализация и синергетический историзм. СПб.: Политехника, 2004.

Бранский, Пожарский (ред.) 2009 - Бранский В.П., Пожарский С.Д. (ред.). Синергетическая философия истории. Рязань: Копи-Принт, 2009.

Бранский и др. 2017 - Бранский В.П., Пожарский С.Д., Микайлова И.Г., Бусов С.В., Зобова М.Р. Глобальное развитие человечества с позиций синергетической философии истории // Вопросы философии. 2017. № 5. С. 55-65.

Князева, Курдюмов 2002 - Князева Е.Н., Курдюмов С.П. Основания синергетики. СПб.: Алетейя, 2002.

Розин 2004 - Розин В.M. Социально-гуманитарные науки и проблема специфики синергетики как научной дисциплины // Философские науки. 2004. № 2. C. 85-102.

Седов 1995 - Седов E.A. Информационно-энтропийные свойства социальных систем // Общественные науки и современность. 1995. № 3. С. $92-100$.

Фокин 2015 - Фокин В.И. Борьба за лидерство и взаимодействие культур // Вестник гуманитарного факультета Санкт-Петербургского государственного университета телекоммуникаций им. проф. М.А. Бонч-Бруевича. 2015. № 7. С. 180-192.

Фурцев web - Фуриев А.И. Корпорация-государство // http://www.Intelros.ru/engine /print.php/ newsid=124\&news (дата обращения: 07.06.2018).

Энгельс 1961 - Энгельс Ф. Анти-Дюринг // Маркс К., Энгельс Ф. Сочинения. 2-е изд. М.: Гос. изд-во полит. лит. 1961. Т. 20. С. 1-338.

Robertson 2000 - Robertson R. Globalization. Social Theory and Global Culture. L.: SAGE Publications Ltd. 2000.
Sheeld (ed.) 2013 - Sheeld J. (ed.). Globalization. Yesterday, Today, and Tomorrow. USA, Emergent publications, 2013.

\section{REFERENCES}

Branskiy V.P., Pozharskiy S.D. Globalization and Synergistic Historicism. Saint-Petersburg, Politekhnika Publ., 2004.

Branskiy V.P., Pozharskiy S.D. (eds.). The Synergistic Philosophy of History (The Collective Monography). Ryazan, Pub. House "KopiPrint", 2009.

Branskiy V.P., Pozharskiy S.D., Mikailova I.G., Busiv S.V., Zobova M.R. The Global Development of Mankind from the Synergetic History Position. Voprosy filosofii-Philosophy issues, 2017, no. 5, pp. 55-65.

Knyazeva E.N., Kurdumov S.P. The Foundations of Synergetics. Saint-Petersburg, Aleteya Publ., 2002.

Rozin V.M. Social and human sciences and the problem of the specificity of synergy as a scientific discipline. Filosofskie nauki - Philosophical Sciences, 2004, no. 2, pp. 85-102.

Sedov E.A. The Information-entropic Properties of Social Systems. Obshchestvennye nauki $i$ sovremennost-Social Sciences and Modernity, 1995, no. 3, pp. 92-100.

Fokin V.I. The Fight for Leadership and Cultural Interaction. Vestnik gumanitarnogo fakulteta Sankt-Peterburgskogo gosudarstvennogo universiteta telekommunikatsiy im. prof. M.A. Bonch-Bruevicha-Bulletin of the Faculty of Humanities of St. Petersburg State University of Telecommunications. prof. M.A. BonchBruevich, 2015, no. 7, pp. 180-192.

Furtsev A.I. Corporation-State. URL: http://www. Intelros.ru/engine/print.php/newsid= 124\&news (accessed 7 June 2018).

Engels F. Anti-Dühring. Karl Marx, Friedrich Engels werke. Band 20. Dietz Verlag. Berlin, 1962, pp. 5-303.

Robertson R. Globalization. Social Theory and Global Culture. London, SAGE Publications Ltd., 2000.

Sheeld J. (ed.). Globalization. Yesterday, Today, and Tomorrow. USA, Emergent publications, 2013. 


\section{Information about the Author}

Alexey F. Rodukov, Candidate of Sciences (Philosophy), Associate Professor, Lecturer, Department of Social and Political Sciences, The Bonch-Bruevich Saint-Petersburg State University of Telecommunications, Prosp. Bolshevikov, 22, Bld. 1, 193232 Saint Petersburg, Russian Federation, a.rodukov@yandex.ru,https://orcid.org/0000-0002-3560-4985

\section{Информация об авторе}

Алексей Федорович Родюков, кандидат философских наук, доцент, преподаватель кафедры социально-политических наук, Санкт-Петербургский государственный университет телекоммуникаций им. проф. М.А. Бонч-Бруевича, просп. Большевиков, 22, к. 1, 193232 г. СанктПетербург, Российская Федерация, a.rodukov@yandex.ru, https://orcid.org/0000-0002-3560-4985 